\title{
Examining the structural relationships of destination image and tourist satisfaction
}

\author{
Hoang Ba Huyen Le ${ }^{a^{*}}$, Thi Binh Le ${ }^{a}$, Huy Chinh Le ${ }^{a}$, Quang Hieu Le ${ }^{a}$, and Chi Thanh Ngo
}

${ }^{a}$ Faculty of Economics and Business Administration, Hong Duc University, Vietnam [Postal Address: No 565, QuangTrung, Dong Ve Ward, ThanhHoa city, ThanhHoa Province, 40000-42000, Vietnam

\section{H R O N I C L E}

Article history:

Received: October 16, 2019

Received in revised format:

January 302020

Accepted: February 10, 2020

Available online:

February 10, 2020

Keywords:

Tourist

Destination image

Satisfaction

\section{A B S T R A C T}

Image destination is one of the most important factors to attract and retain tourists. An enticing destination image promotes the tourist's experience and creates satisfaction that encourages tourists to return. The purpose of this study is to assess the impact of destination image and the factors that constitute the destination image on tourist satisfaction at a tourist destination. Cronbach's Alpha test methods, Exploratory Factor Analysis (EFA), Confirmatory Factor Analysis (CFA) and Structural Equation Modeling (SEM) were used in the study. Primary database was used as a result of the survey involving 500 tourists at the mountainous destinations in Thanh Hoa province. The results of the study demonstrated that destination images positively impact tourists' satisfaction. Based on the study results in the article, we proposed some key solutions to strengthen propaganda and promotion for relevant destinations; to improve the quality of tourism infrastructure; to create and diversify tourism products; to enhance security measures for greater safety and further improvement of tourist satisfaction.

\section{Introduction}

Economic development associates the enhanced competitiveness of tourist destinations, so in order to attract more tourists, the tourist destinations need to create a tourism setting that nurture the tourist satisfaction. Therefore, more and more tourism scholars and researchers attach more importance to the destination image, which acts as the baseline factor affecting tourist satisfaction. According to Crompton (1979), destination image is a combination of ideas and impressions which someone has about a tourist destination. Several surveys have provided that the destination image may have a big effect on absorbing tourists and keeping them happy with a tourist destination (Ali \& Howaidee, 2012; Rajesh, 2013). Nevertheless, there are only a few studies assessing the destination image and the factors building sufficient destination image which could lead to the tourist satisfaction in Vietnam. Thus, it is essential to perform some studies for model concretization through the inheritance of theories, models, and analytical achievements in previous studies. In Vietnam, the Government notified that by 2030 tourism would become a key economic sector. Therfore, it is strongly recommended by tourism experts that relevant tourism agencies not only need to focus on solutions to increase the number of tourists, but also attentively improve the destination image, thereby elevating tourist satisfaction for their prolonged residence, as well as active return to Vietnam in the future (Ba et al., 2020; Government, 2011). Mountainous region in Thanh Hoa province is located in the North Central region of Vietnam, with diverse terrains and favorable conditions for tourism potential. Tourism potential is always the most developed advantage in this region. One of the main factors to attract tourists to the destinations of the mountainous region in Thanh Hoa province is the unique tourist impression, or the feelings during their destination visit. In other words, the destination image is one of the decisive factors for tourists to pick up a destination. Attractive destination images will likely provide tourist satisfaction and allure them to return to the destination later on. Therefore, identification of the components of a destination image provide significant data for destination managers, and tourism business enterprises, to build a concrete plant to appeal tourists and incite their satisfaction with the destination; the reason behind this is because customer satisfaction * Corresponding author. Tel. +84912222345

E-mail address: lehoangbahuyen@hdu.edu.vn (H. B. H. Le) 
is considered as one of the most important drivers of business performance and also one of the important indicators of business success. For these purposes, this study shall analyze the impact of destination image on tourist satisfaction at the mountainous destinations in Thanh Hoa province. Ultimately, we will provide some suggestions and recommendations for tourism businesses and stakeholders at the local level, in order to fulfill tourist satisfaction and match with the diverse needs of tourism development at the mountainous destinations in Thanh Hoa province for the current period.

\section{Literature Review}

\subsection{Destination image and destination image's constituent factors}

Destination image is an attribute of an enchanting tourism destination. Therefore, a good destination image will be a factor that impacts the perception of tourists to a tourism destination. Empirical studies showed a correlation between destination image and tourist satisfaction after experiencing local tourism products and services. In general, it can be observed that if a destination image can prove its enticement and meets the tourists' expectations, they will be likely to achieve even more satisfaction. According to Crompton (1979), destination image is the sum of beliefs, ideas and impressions that a person has about a tourist destination. Research of Ali and Howaidee (2012), indicated that a destination image comprise various components such as: Fresh climate; Fascinating culture; Infrastructure; Facilities and services; seascape; Beautiful beaches. According to Phan (2016), destination image is determined by the following factors: Travel resources, natural features, infrastructure, government support, price perceived. In addition, according to Zeithaml (1988), among the destination image components, price perceived can greatly affect the perception of tourist satisfaction. Beerli and Martin (2004) pointed out that tourism destination image is a concept widely used in empirical studies, but it is poorly defined and has no solid theoretical basis (Mazanec, 1994; Crompton, 1992). In addition, according to Beerli and Martin (2004), through a lot of references to the attributes and attractions of tourist destinations using various scales, a system of generalized components that constitute the image of a destination has been modeled. These factors were classified by Beerli into 9 different aspects, namely: (1) natural resources; (2) general infrastructure; (3) tourist infrastructure; (4) tourist leisure and recreation; (5) culture, history and art; (6) political and economic factors; (7) natural environment; (8) social environment; (9) destination atmosphere. The above aspects represent a tourist destination image. According to Vengesayi (2003), the factors categorized as a destination's resources (tourism resources) and the combination of tourist activities are the basic factors that make up the attractions of a tourism destination and instill a destination image in the mindset of tourists. Specifically, these are natural factors, history, culture, events and tourism and entertainment activities at a destination. According to recent study by Martin and Rose (2008), it has been assumed that the following five factors constitute a destination image: Infrastructure system, climatic conditions, natural conditions, destination impression and cultural environment. As such, it can be seen that the tourist attractiveness delivered by local attributes or destination image was measured by relatively different methods between these studies. Attractiveness can be assessed through infrastructure utilities, services, and culture or local government support and many other attributes.

\subsection{Visitor satisfaction}

Swan and Combs (1976) stated that customer satisfaction was the expression of their attitude after the purchase (e.g., the customer shows the attitude of like or dislike, excitement or non-excitement, satisfaction or dissatisfaction). Meanwhile, Oliver (1997) stated that customer satisfaction was their feelings when the consumption satisfied their needs, expectations and goals in a pleasant and fascinating way. In the field of tourism, Chon (1989) stated that: Tourist satisfaction depends on tourist expectations: whether pre-visit expectations match with ongoing experiences during a visit at a tourism destination (what tourists see, feel and perceive). Concurrently, Chon (1990) realized that: There was a correlation between the tourist expectations on a destination and tourist satisfaction. The correlation can be interpreted like this: after tourists buy tourism products and services, if their reviews on tourism products are better than they expected, they will be likely contented with their trips. Many authors study the nature of customer satisfaction using different approaches, each of which provides a diverse understanding of satisfaction. Satisfaction can be referred to as a result of a comparison between a tourist's perception of the quality of products and services and the his/her level of expectation. Products and services that are offered with higher quality than the price paid and their expectations will likely make them satisfied. Oliver (1999) emphasized that satisfaction is the feeling of consumers when the consumption satisfied their needs, expectations and goals in a pleasant and fascinating way. In general, tourist satisfaction assessment is based on a correlation directly proportional with the quality of the services provided at a destination throughout the course of the tourist perception, whereas the tourist satisfaction is assessed as an crucial factor in the development of leisure activities and tourism activities (Tribe \& Snaith, 1998; Lee, 2009; Mannell \& Iso-Ahola, 1987). In summary, this study uses the concept of tourist satisfaction as a result of quality services provided at a destination.

\subsection{Correlation between destination image and tourist satisfaction}

Destination image is an attribute of an enchanting tourism destination. Therefore, a good destination image will be a factor that impacts the perception of tourists to a tourism destination. Empirical studies showed a correlation between destination image and tourist satisfaction after experiencing local tourism products and services. In general, it can be observed that if a destination image can prove its enticement and meets the tourists' expectations, they will be likely to achieve even more satisfaction. Research by Chon (1990) in the tourism sector also discovered a relationship between tourist expectations and tourist satisfaction, whereas destination image is considered a factor with strong impact on tourist satisfaction. This conclusion 
has been verified by further studies of Ries and Trout (1984). As such, both theory and practice imply that a good destination image shall deliver a positive impact on tourist satisfaction. In other words, destination image is a decisive factor that win the tourist satisfaction at a certain destination. In Mayo's opinion (1973), a tourist destination image is undeniably essential because it influences the decision-making behavior of potential tourists. The image for a destination is an important factor in the selection process as well as affects the satisfaction level during their travel experience.

\section{Research methods and materials}

\subsection{Research models and hypotheses}

The research model is established on the assumptions that the destination image has direct impact on tourist satisfaction with the mountain destinations in Thanh Hoa province as shown in Fig. 1. Through previous studies, it has been affirmed that positive destination image has a significant impact on tourist satisfaction. Thus, it is likely that the relationship between destination image and tourist satisfaction has been mentioned by many studies; as such, the authors hereby proposes the relationship between the destination image and the tourist satisfaction at the mountainous destination in Thanh Hoa province according to the following hypotheses:

H1: Destination image has a proportional impact on tourist satisfaction at the mountain destinations in Thanh Hoa province.

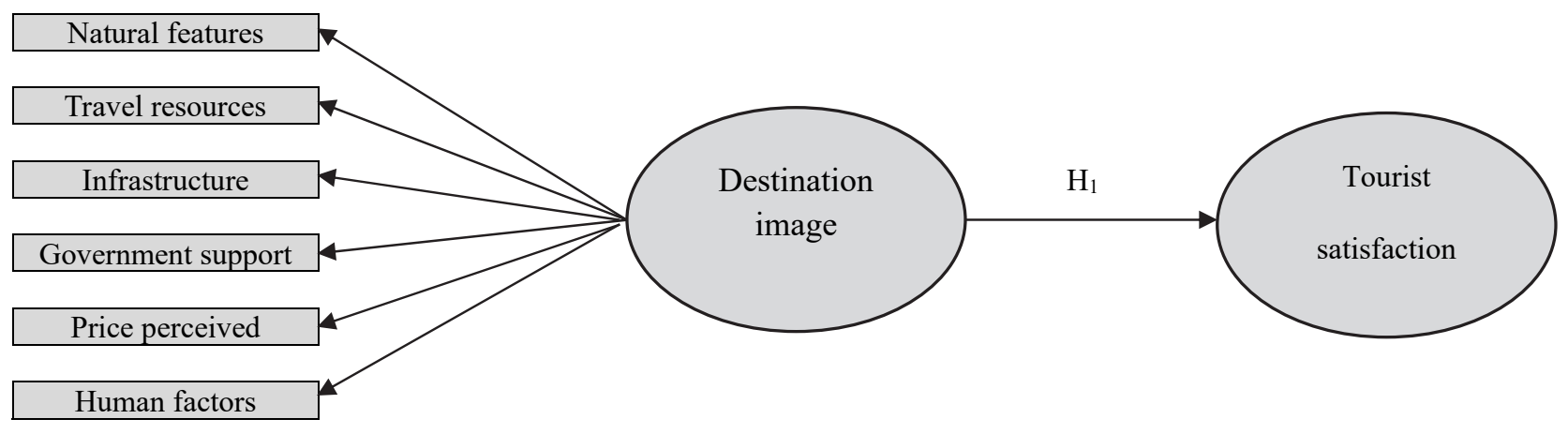

Fig. 1. Model proposed by the authors

\subsection{Description of Study Data}

\subsubsection{Subjects of Study}

Subjects of the study were selected from the tourists at the mountain destinations in Thanh Hoa province. Using nonprobability sampling method, sample subjects were selected based on Black's assessment (2009). We used a 5-point likert scale with 1 being totally disagree and 5 being totally agree. All scale factors are unidirectional.

\subsubsection{Scope of Study Sample}

Hair et al. (1998) recommend that if the sample size is around 100, the loading factor standard must be greater than 0.5. Bollen (1987) proposed the ratio of 5 observations per estimated parameter in the multivariate analysis. In the research, there are 32 variable observations, so the minimum sample size should be equal to $32 \times 5=160$ samples. The study has a sample size of 500 tourists at the mountains tourism destination in Thanh Hoa, which can meet the requirements and be generalizable, representative of the total study; The total number of valid questionnaires collected and processed was 385 questionnaires.

\subsubsection{Survey Method}

The study was conducted through direct interviews and questionnaires with tourists at mountain destinations in Thanh Hoa province using non-probability sampling methods.

\subsubsection{Analytical methods}

The research uses the exploratory factor analysis (EFA), confirmatory factor analysis (CFA), and structural equation model (SEM) with SPSS.20 software in combination with AMOS.20. Cronbach's Alpha testing is used to evaluate the reliability of the scale of variables, and to eliminate the inadequate variables. Exploratory factor analys is for developing a scale and identifying an underlying relationship between measured variables. The confirmatory factor analysis is used to redefine univariate, multivariate, convergent and discriminant values of concepts. From the CFA results, structural equation analysis 
is used to construct and validate relevance of the research model and also assess the impact level of independent variables on the dependent variable.

\subsubsection{Questionnaire}

For this study, the authors design a questionnaire consisting of two parts:

Part 1: General information.

Part 2: Assessment of tourists on the factors constituting the destination image and the level of tourist satisfaction with the destination image at the Thanh Hoa mountain tourism destinations.

\section{Results}

\subsection{Descriptive Statistics}

The study has a sample size of 500 tourists, resulting in a total of 385 valid survey questionnaires collected and processed. Demographic information of the observed sample is presented in Table 1.

Table 1

Description of demographic characteristics of the surveyed sample

\begin{tabular}{|c|c|c|c|}
\hline & Content & Frequency & Percent \\
\hline \multirow{3}{*}{ Gender } & Male & 198 & 51.4 \\
\hline & Female & 187 & 48.6 \\
\hline & Total & 385 & 100.0 \\
\hline \multirow{5}{*}{ Age } & Under 18 & 84 & 21.8 \\
\hline & $19-30$ years & 148 & 38.4 \\
\hline & $31-50$ years & 107 & 27.8 \\
\hline & Above 50 years & 46 & 11.9 \\
\hline & Total & 385 & 100.0 \\
\hline \multirow{5}{*}{ Income } & Under 5 million & 113 & 29.4 \\
\hline & 5-10 million & 180 & 46.8 \\
\hline & $11-15$ million & 57 & 14.8 \\
\hline & over 15 million & 35 & 9.1 \\
\hline & Total & 385 & 100.0 \\
\hline \multirow{4}{*}{ Education } & College, high school or lower & 95 & 24.7 \\
\hline & Bachelor degree & 242 & 62.9 \\
\hline & Post graduate degree & 48 & 12.5 \\
\hline & Total & 385 & 100.0 \\
\hline
\end{tabular}

\subsection{Assessment of destination image on tourist satisfaction}

\subsubsection{Test of the Reliability of Scale}

One of the popular methods for testing the reliability of a scale is to test the Cronbach's Alpha coefficient. Cronbach's Alpha coefficient will be run separately for each independent factor, thereby measuring the consistency among the variables of the same factor because the higher and higher the consistency of observed variables is, the higher the reliability of the scale is. In this study, each factor, when being tested, must have Cronbach's Alpha score of 0.6 and over to be considered acceptable. If the factor's Cronbach's Alpha score reaches from 0.7 to 0.8 , it can be used and if it ranges from 0.8 to 1 , the reliability is high (Hair et al., 1998). Meanwhile, the item-total correlation coefficient of each variable must reach 0.3 and over to be included in the next analysis. The variables, the coefficient of which is less than 0.3 , will be considered as non-informative variable and excluded before the factor analysis. Software SPSS.20 was used to support the analysis of the data collected after exclusion. The authors excluded 4 variables NAT4, NAT 5, TRA6, TRA7 due to their Cronbach's Alpha coefficients $<0.3$ (Hair et al., 1998). The remaining 25 independent variables and 3 dependent variables are included in the EFA model.

\subsubsection{Analysis of Exploratory Factor}

Principal Axis Factoring was used with Promax rotation (Anderson \& Gerbing, 1988) and factor loading coefficients $\geq 0.5$ to incorporate remaining variables into Exploratory Factor Analysis (EFA) model for the purposes of scale validation (Hair et al., 1998). We have the resultant KMO coefficient $=0.873>0.5$; Bartlett's Test statistics are 4794,348 with significance level of $0,000<0.05$; Cumulative of Variance is $73.237 \%$ ( $>50 \%$ ). This proves that the analytical data is perfectly relevant. Thus, all factor loading coefficients are greater than 0.5 ; explained variance is greater than $50 \%$, the observed variables are grouped exactly as the original scale. It is shown in the EFA results the following factors:

Factor 1: includes the observed variables TRA1-TRA5 (except TRA6, TRA7) and is named "Travel resources" (TRA). Factor 2: includes observed variables INF1-INF5 and is named "Infrastructure" (INF).

Factor 3: includes observed variables GOV1-GOV4 and is named "Government support" (GOV). 
Factor 4: includes observed variables PRI1-PRI4 and is named "Price perceived" (PRI). Factor 5: includes observed variables HUM1-HUM4 is named "Human factors" (HUM).

Factor 6: includes observed variables NAT1-NAT3 (except NAT4, NAT5) is named "Natural features" (NAT). Factor 7: includes observed variables SAT1-SAT3 is named "Satisfaction" (SAT).

After EFA exploratory analysis, it can be seen that the model has no difference from the research model, only some observed variables are unreliable so they are excluded from the study variable. There is no new factor group as Table 2 follows:

Table 2

Analysis result of the second exploratory factor

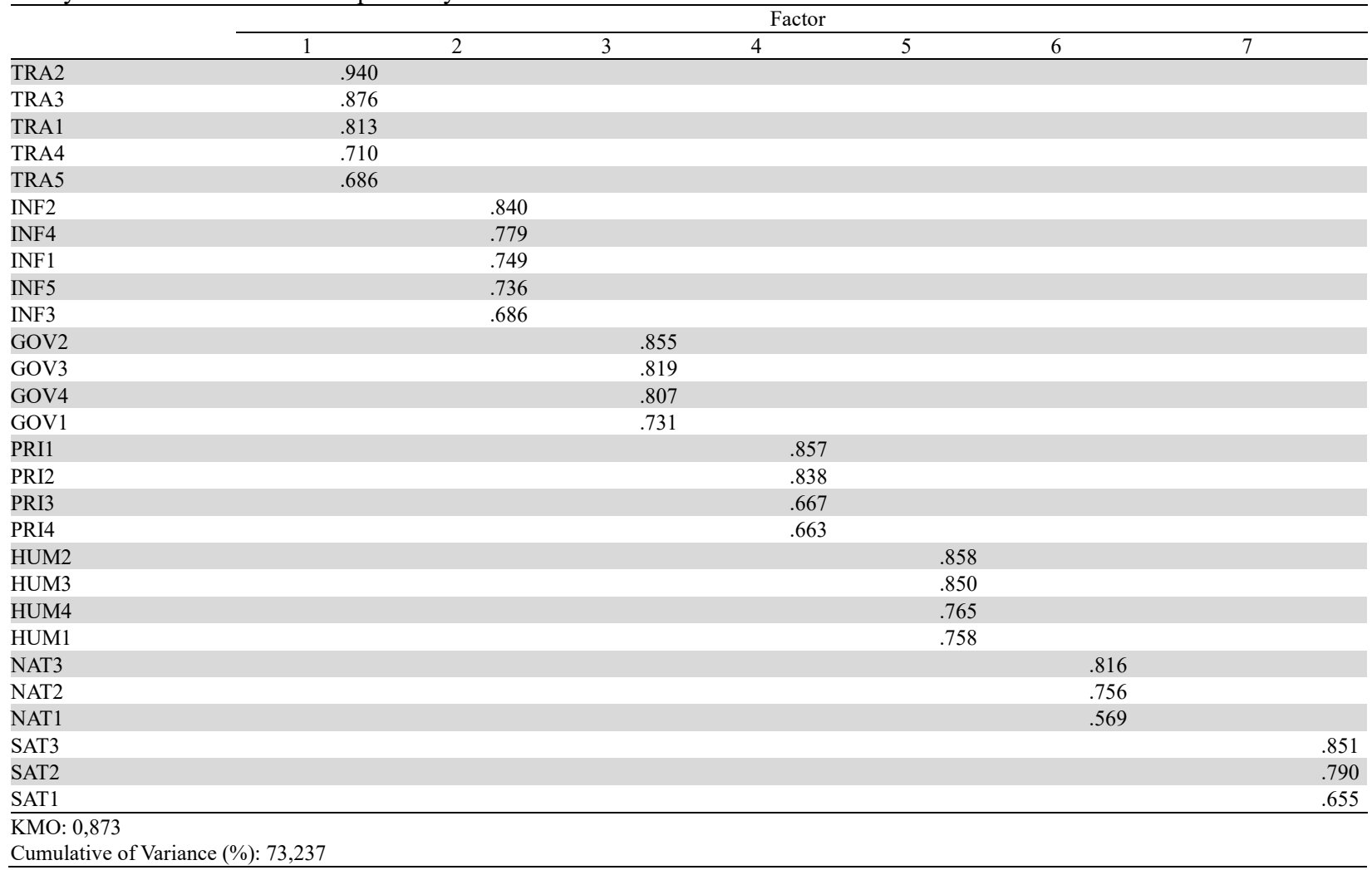

\subsubsection{Analysis of Confirmatory Factor}

It can be seen in the EFA results that there are eight key concepts in the research model. To measure the model's suitability with market information, we use Chi-square (CMIN), which is adjusted by degrees of freedom (CMIN/df), CFI, GFI, TLI and RMSEA indices. The model is considered to be suitable with the market data when it receives TLI, CFI $\geq 0.9$; GFI $\geq 0.8$ (Bentler \& Bonelt, 1980), CMIN/df $\leq 3$ (Carmines, 1981) RMSEA $\leq 0.08$ (Steiger, 1990). It is shown in the CFA results of the research model that it is suitable with the market information (Fig. 2). P-value results of the observed variables representing the factors all have the value sig. $=0.000$ so the observed variables are affirmatively considered to have good representation for the CFA model factor. The correlation coefficient of each pair of concepts is different from 1 in the reliability of $95 \%$ (PValue value $=0.000)$ so the concepts achieve discriminant value. The weights (normalized) all are more than 0.5 and weights (non-normalized) are statistically significant (sig. $<0.000)$ so the concepts achieve convergence value. This measurement model is compatible with market data and there is no correlation among measurement errors so it achieves uniqueness. The critical measurement model for research concepts is shown in Figure 2. The critical model is a model of established factors that are freely interrelated. CFA analysis results demonstrate that: Chisquare $/ \mathrm{df}=2.084<3$ (Carmines, 1981), degree of freedom $\mathrm{df}=329, \mathrm{CFI}=0.923, \mathrm{TLI}=0.911>0.9($ Bentler $\&$ Bonelt, 1980); GFI $=0.850>0.8 ;$ and $\mathrm{RMSEA}=0.063<0,8$ (Steiger, 1990). All factor weights of each observed variable are greater than 0.5, so it can be viewed that the model achieves convergence value (See Fig. 2).

Analysis results indicate that: Correlation coefficients are less than 1, covariance validation and correlation between pairs of variables are statistically significant $(\mathrm{p}<0.05$, table 1$)$. It can be seen that the model factors achieve discriminant value (See Table 3). 


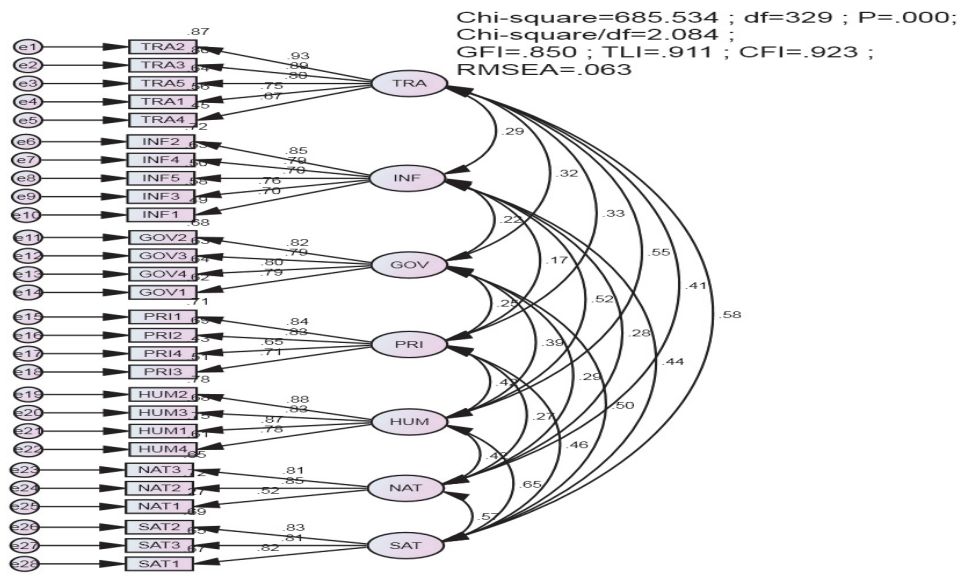

Fig. 2. Results of CFA of the organizational culture scale (standardized)

Table 3

Coefficient of correlation, covariance between variables

\begin{tabular}{|c|c|c|c|c|c|c|}
\hline \multicolumn{3}{|c|}{ Factor } & \multirow{2}{*}{$\begin{array}{c}\text { Estimate } \\
.212\end{array}$} & \multirow{2}{*}{$\begin{array}{l}\text { S.E. } \\
.051\end{array}$} & \multirow{2}{*}{$\begin{array}{l}\text { C.R. } \\
4,127\end{array}$} & \multirow{2}{*}{$\frac{\mathbf{P}}{* * *}$} \\
\hline TRA & $\leftrightarrow$ & INF & & & & \\
\hline TRA & $\leftrightarrow$ & GOV & .230 & .052 & 4,443 & $* * *$ \\
\hline TRA & $\leftrightarrow$ & PRI & .231 & .051 & 4,557 & $* * *$ \\
\hline TRA & $\leftrightarrow$ & HUM & .398 & .056 & 7,169 & $* * *$ \\
\hline TRA & $\leftrightarrow$ & NAT & .253 & .048 & 5,279 & $* * *$ \\
\hline TRA & $\leftrightarrow$ & SAT & .424 & .059 & 7,235 & $* * *$ \\
\hline INF & $\leftrightarrow$ & GOV & .155 & .051 & 3,037 & .002 \\
\hline INF & $\leftrightarrow$ & PRI & .120 & .049 & 2,426 & .015 \\
\hline INF & $\leftrightarrow$ & HUM & .370 & .056 & 6,586 & $* * *$ \\
\hline INF & $\leftrightarrow$ & NAT & .172 & .046 & 3,708 & $* * *$ \\
\hline INF & $\leftrightarrow$ & SAT & .313 & .056 & 5,587 & $* * *$ \\
\hline GOV & $\leftrightarrow$ & PRI & .173 & .050 & 3,446 & $* * *$ \\
\hline GOV & $\leftrightarrow$ & HUM & .277 & .053 & 5,216 & $* * *$ \\
\hline GOV & $\leftrightarrow$ & NAT & .176 & .046 & 3,807 & $* * *$ \\
\hline GOV & $\leftrightarrow$ & SAT & .356 & .058 & 6,152 & $* * *$ \\
\hline PRI & $\leftrightarrow$ & HUM & .294 & .053 & 5,580 & $* * *$ \\
\hline PRI & $\leftrightarrow$ & NAT & .159 & .045 & 3,534 & $* * *$ \\
\hline PRI & $\leftrightarrow$ & SAT & .318 & .055 & 5,748 & $* * *$ \\
\hline HUM & $\leftrightarrow$ & NAT & .258 & .048 & 5,346 & $* * *$ \\
\hline HUM & $\leftrightarrow$ & SAT & .462 & .061 & 7,594 & $* * *$ \\
\hline NAT & $\leftrightarrow$ & SAT & .348 & .054 & 6,459 & $* * *$ \\
\hline
\end{tabular}

\subsubsection{Test of Reliability after Exploratory Factor Analysis}

It can be seen after Cronbach's Alpha test that Cronbach's Alpha coefficient of each factor has a value of more than 0.7 and the item-total correlation coefficient is more than 0.3 , therefore, the scales all are reliable. The combined reliability and Average Variance Extracted of each factor have values greater than 0.5 (See Table 4) so the factors in the model are reliable.

Table 4

Test results of reliability of the scale

\begin{tabular}{|c|c|c|c|c|c|}
\hline Factor & $\begin{array}{c}\text { Number of } \\
\text { observed } \\
\text { variables }\end{array}$ & $\begin{array}{l}\text { Cronbach's Alpha } \\
\text { reliability }\end{array}$ & $\begin{array}{c}\text { Combined } \\
\text { reliability }(\mathrm{CR})\end{array}$ & $\begin{array}{c}\text { Average Variance } \\
\text { Extracted } \\
\text { (AVE) }\end{array}$ & $\begin{array}{c}\text { Convergence and } \\
\text { discriminant values }\end{array}$ \\
\hline Natural features (NAT) & 3 & 0,764 & 0,775 & 0,545 & Satisfactory \\
\hline Travel resources (TRA) & 5 & 0,906 & 0,907 & 0,665 & Satisfactory \\
\hline Infrastructure (INF) & 5 & 0,874 & 0,860 & 0,585 & Satisfactory \\
\hline Government support (GOV) & 4 & 0,873 & 0,876 & 0,639 & Satisfactory \\
\hline Price perceived (PRI) & 4 & 0,844 & 0,848 & 0,585 & Satisfactory \\
\hline Human factors (HUM) & 4 & 0,903 & 0,905 & 0,705 & Satisfactory \\
\hline Satisfaction (SAT) & 3 & 0,854 & 0,858 & 0,668 & Satisfactory \\
\hline
\end{tabular}

\subsubsection{Structural Equation Modeling (SEM)}

The study used SEM linear structure model to evaluate the suitability of the research model and to validate the correlations in the model. SEM analysis results with the degree of freedom $\mathrm{df}=343$, Chi-square $=709,164$ with $\mathrm{p}=0,000<0,05$, Chi- 
square $/ \mathrm{df}=2,068<3, \mathrm{CFI}=0,920, \mathrm{TLI}=0,905>0,9 ; \mathrm{GFI}=0,846>0,8 ; \mathrm{RMSEA}=0,063<0,8$. Therefore, it can be confirmed that the model is well suited to the market data (See Fig. 3)

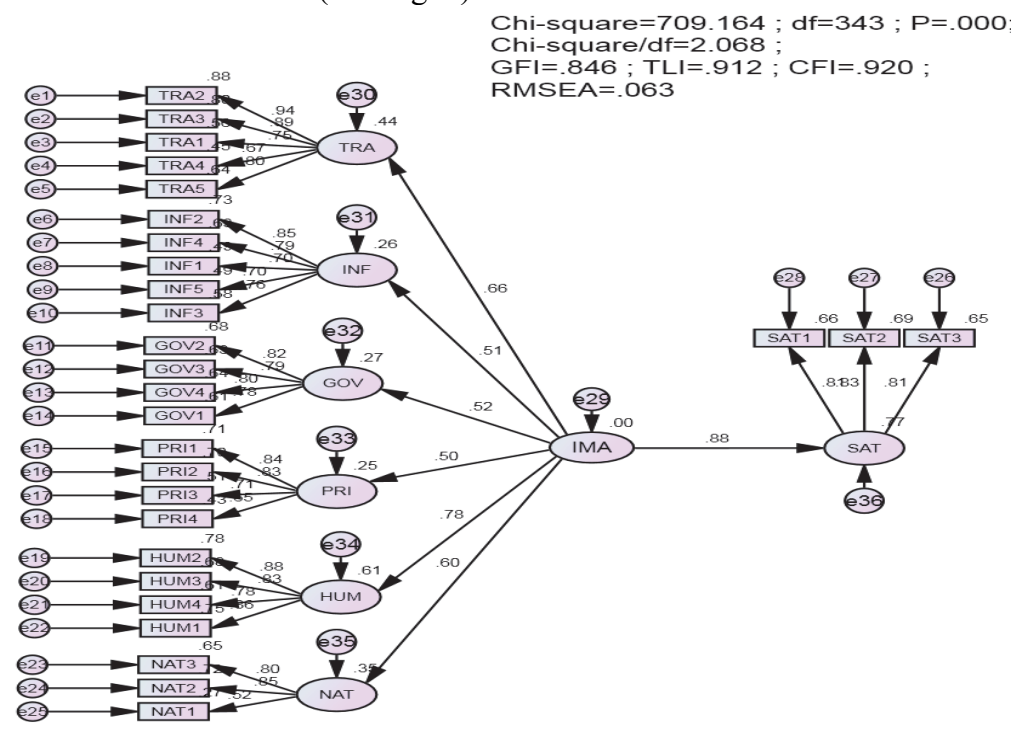

Fig. 3. Standardized Structural Equation Modeling (SEM)

The SEM regression results in Table 4 with $\mathrm{P}<5 \%$ confirm that the hypothesis $\mathrm{H}_{1}$ is accepted, meaning that the destination image (IMA) has a positive impact on tourist satisfaction (SAT) at the mountainous tourism destination in Thanh Hoa province.

Table 5

Coefficients of regression model SEM and test results of the model's hypotheses

\begin{tabular}{|c|c|c|c|c|c|c|c|c|}
\hline Hypothesis & & Factor & & Estimate & S.E. & C.R. & P-value & Result \\
\hline $\mathrm{H} 1$ & SAT & $\leftarrow$ & IMA & 0,880 & 0,111 & 9.1678 & $* * *$ & Acceptable \\
\hline
\end{tabular}

\section{Recommendations}

In conjunction with numerous findings in the service sector, destination image and satisfaction are proportionally related (Lee, 2009; Marzuki \& Hay 2013; Phan, 2016). Drawn from the above findings, we hereby would like to come up with some recommendations to tourism agencies and organizations at the mountainous destinations in Thanh Hoa province. For greater tourist satisfaction with mountain destinations in Thanh Hoa province, it is strongly recommended to maintain the constant improvement of destination image by improving various elements. First, strengthening destination propaganda and promotion. To realize the aforesaid target, adequate propaganda and advertisement campaigns should be targeted at tourists who visit Thanh Hoa mountains in order to elicit their desire to have an immerse experience in the daily life of the local community, enjoy regional specialties such as Co Lung Duck, Song Ma Hemibagrus Fish, Buffalo Meat with Lom leaves, Bitter Soup, Straw Liquor, etc. At the same time, the restoration of traditional craft villages should be focused to provide souvenir products for tourists, thus meeting their tourism needs and raising incomes for local people. Second, improving the quality of tourism infrastructure. Concretely, hotel and restaurant services should be adequately provided in proportion with service prices; a pricing strategy is required along with associated policies such as: promotions, discounts (room rates, tour prices, etc.), so the tourists have a solid perception of more competitive price at the mountainous destinations in Thanh Hoa province. Third, building and diversifying tourism products. Building more compelling recreation centers and parks; the destinations at the mountainous region in Thanh Hoa province should be focused on unique natural landscapes; many charming and famous scenic spots with beautiful landscapes and environment; pollution-free environment; amorous hills and mountains. Finally, strengthen security to ensure safety for tourists. Security is at all times considered one of the most concerns by tourists during their destination pickup. To attract both domestic and international tourists, it is a prerequisite that a locality must first ensure the their safety throughout the exploratory trips. Tourist safety is not only represented by the tranquility at the destination, but also by the measures of the local authorities against thieves, crimes, traffic accidents, etc. The scope of this study is limited to tourists at the destinations of the mountainous area in Thanh Hoa province. On the other hand, no correlation with other nearby localities has been conducted to assess the differences among localities. Therefore, the study results shall not be used to generalize all tourist destinations across the country. On the other hand, the scope of study is only concentrated in the mountainous areas in Thanh Hoa province. Differences in: climate, nature, resources, etc. are to be expected. As such, the study results are to some extent different from those for other tourist destinations in the country. Furthermore, the study has just revolved around the impact of destination image on tourist satisfaction. As we all know, the satisfaction is also ruled by many other aspects (e.g. price perceived; quality of products and services offered by the destination, etc.). Therefore, apart from the impact of destination image, more studies on other factors affecting tourist satisfaction are highly recommended. 
The above limitations are also the gaps that successive researchers are encouraged to address and work on for a more satisfactory and comprehensive solution.

\section{References}

Ali, J. A., \& Howaidee, M. (2012). The impact of service quality on tourist satisfaction in Jerash. Interdisciplinary Journal of contemporary research in business, 3(12), 164-187

Anderson, J. C., \& Gerbing, D. W. (1988). Structural equation modeling in practice: A review and recommended two-step approach. Psychological Bulletin, 103(3), 411.

Ba, H., Thu, P., Chi, T., Thanh, H., \& Huy, C. (2020). Solutions to attract investment capital for tourism development: Evidence from Vietnam economy. Accounting, 6(2), 209-214.

Beerli, A., \& Martin, J. D. (2004). Factors influencing destination image. Annals of Tourism research, 31(3), 657-681.

Bentler, P. M., \& Bonett, D. G. (1980). Significance tests and goodness of fit in the analysis of covariance structures.Psychological Bulletin, 88(3), 588

Black, K. (2009). Business statistics: Contemporary decision making. John Wiley \& Sons.

Bollen, K. (1987). Sample size and Bentler and Bonett's nonnormed fit index. Psychometrika, 52(1), 161-161.

Carmines, E. G. (1981). Analyzing models with unobserved variables. Social measurement: Current issues, 80.

Chon, K. S. (1989). Understanding recreational traveler's motivation, attitude and satisfaction. The Tourist Review, 44(1), 37.

Chon, K. S. (1990). The role of destination image in tourism: A review and discussion. The tourist review.

Crompton, J. L. (1979). An assessment of the image of Mexico as a vacation destination and the influence of geographical location upon that image. Journal of Travel Research, 17(4), 18-23.

Government (2011), Decision No. 2473 / QD-TTg of the Prime Minister on Approving Vietnam's tourism development strategy to 2020, with a vision to 2030, issued on December 30, 2011.Chon, K. S. (1989).

Hair, J. F., Black, W. C., Babin, B. J., Anderson, R. E., \& Tatham, R. L. (1998). Multivariate data analysis (Vol. 5, No. 3, pp. 207-219). Upper Saddle River, NJ: Prentice hall.

Lee, T. H. (2009). A structural model for examining how destination image and interpretation services affect future visitation behavior: a case study of Taiwan's Taomi eco-village. Journal of Sustainable Tourism, 17(6), 727-745.

Mannell, R. C., \& Iso-Ahola, S. E. (1987). Psychological nature of leisure and tourism experience. Annals of Tourism Research, 14(3), 314-331.

Martin, J. R., \& Rose, D. (2008). Procedures and Procedural Recounts. Genre Relations: Mapping Culture. London: equinox.

Marzuki, A., \& Hay, I. (2013). Towards a public participation framework in tourism planning. Tourism Planning \& Development, 10(4), 494-512.

Mayo, E. J. (1973). Regional Images and Regional Travel Behaviour "The Travel Research Association fourth Annual Conference Proceedings. Sun Valley, Idaho.

Mazanec, J. A. (1994). Image measurement with self - organizing maps: A tentative application to Austrian tour operators. The Tourist Review.

Oliver, R. L. (1997). Satisfaction: A Behavioral Perspective on the Consumer. New York: The McGrawHill Companies.

Oliver, R. L. (1999). Whence consumer loyalty?. Journal of marketing, 63(4_suppl1), 33-44.

Phan, M. D (2016), 'Destination image, psychosocial values impact on the satisfaction and loyalty of tourists to Da Lat', PhD thesis, University of Economics Ho Chi Minh City.

Rajesh, R. (2013). Impact of tourist perceptions, destination image and tourist satisfaction on destination loyalty: a conceptual model. PASOS. Revista de Turismo y Patrimonio Cultural, 11(3), 67-78.

Ries, A., \& Trout, J. (1984). Positioning: la conquista della posizione vincente. McGraw-Hill Book Company.

Steiger, J. H. (1990). Structural model evaluation and modification: An interval estimation approach. Multivariate behavioral research, 25(2), 173-180.

Swan, J. E., \& Combs, L. J. (1976). Product Performance and Consumer Satisfaction: A New Concept: An Empirical Study Examines the Influence of Physical and Psychological Dimensions of Product Performance on Consumer Satisfaction.Journal of marketing, 40(2), 25-33.

Tribe, J., \& Snaith, T. (1998). From SERVQUAL to HOLSAT: holiday satisfaction in Varadero, Cuba. Tourism management,19(1), 25-34.

Vengesayi, S. (2003, December). Destination Attractiveness and Destination Competitiveness: A Model of Destination evaluation. In ANZMAC 2003 Conference Proceedings Adelaide (pp. 1-3).

Zeithaml, V. A. (1988). Consumer perceptions of price, quality, and value: a means-end model and synthesis of evidence. Journal of marketing, 52(3), 2-22.

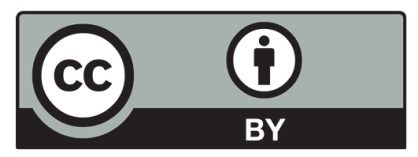

(C) 2020 by the authors; licensee Growing Science, Canada. This is an open access article distributed under the terms and conditions of the Creative Commons Attribution (CC-BY) license (http://creativecommons.org/licenses/by/4.0/). 